\title{
Agroquímicos: su impacto en la legislación y jurisprudencia bonaerense
}

\author{
Juan Ignacio Moreno ${ }^{1}$ | Universidad Nacional de La Plata \\ Revista Derechos en Acción ISSN 2525-1678/ e-ISSN 2525-1686 \\ Año 4/No 12 Invierno 2019 (21 junio a 20 septiembre), 559-579 \\ DOI: https://doi.org/10.24215/25251678e319
}

\section{Introducción}

Es necesario partir de un concepto sobre los plaguicidas para analizar su alcance e importancia en la actividad agropecuaria argentina. Según la Organización de las Naciones para la Alimentación y la Agricultura (FAO) se entiende por plaguicida:

"cualquier sustancia o mezcla de sustancias destinadas a prevenir, destruir o controlar cualquier plaga, incluyendo los vectores de enfermedades humanas o de los animales, las especies no deseadas de plantas o animales que causan perjuicio o que interfieren de cualquier otra forma en la producción, elaboración, almacenamiento, transporte o comercialización de alimentos, productos agrícolas, madera y productos de madera o alimentos para animales, o que pueden administrarse a los animales para combatir insectos, arácnidos u otras plagas en o sobre sus cuerpos[..]". (Código Internacional de Conducta para la Distribución y Utilización de Plaguicidas, art.2)

También se consideran plaguicidas a las sustancias que regulan el crecimiento de plantas, las que evitan la caída prematura de las frutas como las aplicadas a los cultivos contra su deterioración en su almacenamiento y transporte (Código

\footnotetext{
Juan Ignacio Moreno, Facultad de Ciencias Jurídicas y Sociales de la Universidad Nacional de La Plata. Contacto: ignacio_moreno@live.com.ar
} 
Internacional de Conducta para la Distribución y Utilización de Plaguicidas, art.2). Por ende, en un primer acercamiento, se denota la relación directa entre productividad y eficacia de la actividad agraria a través de la utilización de los plaguicidas.

Respecto a su destino de aplicación y como se desprende de dicho artículo, se clasifican en herbicidas, insecticidas y acaricidas, funguicidas y bactericidas. Los herbicidas son utilizados para el control de especies vegetales, como las malezas, que afectan a la producción. En el caso de los insecticidas tienen como fin el control de los insectos perjudiciales para los cultivos. Los últimos plaguicidas cumplen la función de combatir ácaros, hongos y enfermedades bacterianas.

Los plaguicidas pueden clasificarse en Bioinsumos y Agroquímicos. Según el Comité Asesor en Bioinsumos de Uso Agropecuario (CABUA) los bioinsumos, bajo Resolución 29/2016 del Ministerio de Agroindustria de la Nación, son entendidos como el producto biológico que consiste o se haya producido por microorganismos, como hongos, o macroorganismos, como ácaros, o compuestos bioactivos derivados de ellos destinado a ser utilizado como insumo de la producción agropecuaria ${ }^{2}$.

Mientras que los agroquímicos son insumos químicos desarrollados por industrias farmacéuticas y químicas. Considerando el impacto en la salud humana, la biodiversidad y el ecosistema, los agroquímicos se han clasificado por la Organización Mundial de la Salud (OMS) según su grado de peligrosidad y toxicidad en:

De baja peligrosidad: son aquellos que por inhalación, ingestión o penetración cutánea no generan riesgos apreciables.

Tóxicos: los cuales por inhalación, ingestión o penetración cutánea pueden entrañar riesgos de gravedad limitada.

\footnotetext{
2 Los bioinsumos integran un sistema de producción vinculado a la conservación y descanso del suelo, la reducción de insumos químicos como la rotación de cultivos conocido como agroecología. Desde esta visión se busca evitar las consecuencias antrópicas sobre el ambiente utilizando los propios elementos de la naturaleza como realizaban las comunidades originarias del continente americano.
} 
Nocivos: aquellos que por los medios anteriormente expuestos pueden entrañar riesgos graves, agudos o crónicos, e incluso muerte.

Muy tóxicos: con las mismas consecuencias que el grado anterior.

A continuación, se acompaña el cuadro anexo sobre la clasificación de la OMS según el grado de peligrosidad de los fitosanitarios y los colores identificatorios a cada categoría. ${ }^{3}$

\begin{tabular}{|l|l|l|}
\hline \multicolumn{3}{|c|}{ Banda de color de las etiquetas según la categoría toxicológica } \\
\hline \multicolumn{1}{|c|}{ Color de la Banda } & \multicolumn{1}{|c|}{$\begin{array}{c}\text { Clasificación de la OMS } \\
\text { según los riesgos }\end{array}$} & $\begin{array}{c}\text { Clasificación } \\
\text { del Peligro }\end{array}$ \\
\hline Rojo (PMS 199 C) & I a - Producto Sumamente Peligroso & MUY TÓXICO \\
\hline Rojo (PMS 199 C) & I b - Producto Muy Peligroso & TÓXICO \\
\hline Amarillo (PMS Amarillo C) & II - Producto Moderadamente Peligroso & NOCIV0 \\
\hline Azul (PMS 293 C) & Producto Poco Peligroso & CUIDADO \\
\hline Verde (PMS 347 C) & $\begin{array}{l}\text { IV - Producto que Normalmente no } \\
\text { Ofrece Peligro }\end{array}$ & CUIDADO \\
\hline
\end{tabular}

\section{Un poco de historia}

Tras la finalización de la Segunda Guerra Mundial surgieron teorías neomalthusianas que propiciaban el apocalipsis respecto a la producción de alimentos. Dichas teorías planteaban la existencia de un incremento desproporcional de las poblaciones, a nivel global, en comparación a la producción de alimentos necesaria para abastecer a todas las comunidades del planeta. Frente esta postura surgió en los años `60 un cambio de paradigma en la agricultura autodenominado la Revolución Verde, término acuñado por William Guad (administrador de la Agencia Estadounidense para el Desarrollo Internacional-USAID), vinculado a las variedades de cultivos con mayor rendimiento.

3 Clasificación toxicológica de los plaguicidas por la OMS. Cuadro disponible en el link: https://ambiente.lapampa.gob.ar/images/stories/CDLibro/pdfs/anexoB.pdf Último acceso 18/5/19. 
Con el apoyo de las Fundaciones Ford y Rockefeller, quienes crearon el Centros Internacionales de Investigación Agrícola en Estados Unidos, se desarrollaron variedades de arroz y maíz más resistentes. (Sarandón, 2014)

Desde una mirada antropocéntrica y dentro del sistema productivo capitalista, se impulsó la maximización de la producción de alimentos para obtener mayor eficacia y rentabilidad de los cultivos mediante la utilización de insumos químicos. Esta agricultura industrial fue desarrollada por multinacionales vinculadas a la industria farmacéutica, como Syngenta y Bayer, y químicas, representadas por Monsanto y Dupont, quienes gestaron la creación de semillas genéticamente modificadas (dichas semillas sufren una alteración en su cadena de ADN por parte de los seres humanos para potenciar su rendimiento al cultivarse) elaboradas en laboratorios. (Gutman, 2012)

Las semillas genéticamente modificadas fueron el puntapié para el establecimiento de una actividad agropecuaria intensiva e integran un paquete tecnológico para lograr su eficacia. Este paquete tecnológico consiste en la utilización de fertilizantes y agroquímicos en vías de un control efectivo de plagas, enfermedades y malezas; a su vez comprende la implementación de la práctica de siembra directa a través de la cual no se deja descansar el suelo, como en la técnica del barbecho, pasando a una aplicación directa de agroquímicos y semillas sin arar la tierra. Además, esta agricultura industrial propulsa la implementación del monocultivo concentrando la producción agrícola en el cultivo que sea el commodity/mercancía del momento.

Las principales consecuencias en este modelo de producción industrial se perciben:

- En los alimentos porque quedan residuos tóxicos de los agroquímicos en frutas y verduras superando los niveles de tolerancia que determina el SENASA, el cual no posee el personal suficiente para realizar los controles de manera integral. Durante el periodo 2011-2013 el 98\% de las partidas de peras que fueron analizadas en el Merado Central de Buenos aires 
contenía más de 20 variedades de insecticidas y funguicidas. En la actualidad más del $60 \%$ de las verduras y frutas que llegan al Mercado Central contiene residuos de agroquímicos. (incluso han detectado sustancias como el "endosulfán" que se encuentra prohibida para la producción de alimentos. ${ }^{4}$ )

- En el agua como sucedió en la localidad de Pergamino, provincia de Buenos Aires, que se ha visto afectada por fumigaciones de agroquímicos detectándose presencia de glifosato en la orina de distintos vecinos, reacciones en la piel de los niños y pérdidas de embarazos en zonas fumigadas 5 . Ante el reclamo judicial de las familias, Carlos Villafuerte Ruzo (titular del Juzgado Federal №2 de San Nicolás) dispuso la suspensión de la aplicación de estos tóxicos que repercutieron negativamente en la salud de tres barrios de Pergamino. ${ }^{6}$

4 Informe realizado por el biólogo Sergio Federovisky para el medio Infobae del día 11/2/19 bajo el título "Más de la mitad de la verdura que llega al Mercado Central queda descartada por exceso de agrotóxicos detectado en sus laboratorios" Disponible en el link: https://www.infobae.com/tendencias/ecologia-y-medio-ambiente/2019/02/11/masde-la-mitad-de-la-verdura-que-llega-al-mercado-central-queda-descartada-por-exceso-deagrotoxicos-detectado-en-sus-laboratorios/ Último acceso 1/6/2019

5 Nota realizada por el medio Infobae del día 11/4/2019 bajo el título "Contaminación de agua y graves problemas de salud: ordenaron suspender la fumigación con agroquímicos en Pergamino" que recepta las enfermedades ocasionadas por las fumigaciones en la localidad bonaerense. Disponible en el link: https://www.infobae.com/sociedad/2019/04/10/ contaminacion-del-agua-y-graves-problemas-de-salud-ordenaron-suspender-la-fumigacioncon-agroquimicos-en-pergamino/ Último acceso 1/6/2019

6 Luego especialistas del INTA Balcarce, CONICET y el Dr. Damián Marino (UNLP) realizaron un estudio y detectaron la presencia de altos niveles de agroquímicos en el agua potable que consumían los vecinos de fumigaciones. Los intereses de las corporaciones son visibles y trataron de desprestigiar este resultado científico desde la Autoridad del Agua Bonaerense (ASA). Tras la postura en contrario del informe de ASA, el Juez Villafuerte Ruzo solicitó al equipo de Toxicología de la Corte Suprema de la Nación que realizará estudios sobre el agua quienes finalmente analizaron, sobre pruebas líquidas, y constataron que el agua de la localidad de Pergamino contenía 18 agroquímicos hecho que generaba un riesgo para la salud. Claramente el resultado del equipo de Toxicología de la CSJN ratificó la expuesto en el primer informe efectuado por destacados científicos e investigadores del CONICET, INTA-Balcarce y UNLP. Nota del medio Perfil del día 16/4/19 bajo el título "Peritos de la Corte Suprema confirman que el agua de Pergamino contiene 18 agroquímicos" Disponible en el link: www.perfil.com/noticias/sociedad/ 
- En el suelo porque su aplicación directa, sin periódos de carencia, ocasionan una erosión de los mismos que deriva en una pérdida de su capacidad productiva; dependencia a combustibles fósiles; pérdida de la biodiversidad como el caso de las abejas que por el uso del herbicida glifosato perciben una alteración en el sabor de los cultivos interfiriendo en la capacidad de polinización y producción de $\operatorname{miel}^{7}$, desaparición de variedad de cultivos a causa del sistema de monocultivo, mayor dependencia de insumos químicos que implican un gasto económico constante para cada producción agraria.

En el caso de la Argentina durante los años '90 se consolida este modelo de agricultura industrial en consonancia con el avance biotecnológico global. En el año 1991 se suscitan dos legislaciones que permiten una apertura respecto a la biotecnología aplicada a la producción agrícola mediante la creación de la Comisión Nacional Asesora de Bioseguridad (CONABIA) por resolución 124/91 de la Secretaría de Agricultura, Ganadería y Pesca de la Nación con la función de regular y evaluar las actividades realizadas con los organismos genéticamente modificados para garantizar la bioseguridad del agroecosistema. La segunda normativa fue la creación del Instituto Nacional de Semillas (INASE) por el decreto 2817/91 como órgano de aplicación de la Ley de Semillas y Creaciones Fitogenéticas 20247/73 y cuyo objetivo consistía en promover una producción y comercialización eficiente de semillas para garantizar. al productor, la identidad y calidad de la semilla y la protección de la propiedad de las creaciones fitogenéticas. Finalmente, contando con un marco legal sobre semillas, en el año 1996 el Secretario de Agricultura, Pesca y Alimentación de Nación, Felipe Solá, firmó

corte-suprema-confirmo-contaminacion-agua-pergamino-tiene-18-agroquimicos-riesgosalud-humana.phtml Último acceso 1/6/2019

7 Nota del medio infocampo.com.ar, del día 17/8/2018, bajo el título "Confirman que dos agroquímicos interfieren en la polinización de las abejas" Disponible en el link: https://www. infocampo.com.ar/confirman-que-dos-agroquimicos-interfieren-en-la-polinizacion-de-lasabejas/ Último acceso 18/5/19 
la resolución 167/96 que autorizó la producción y comercialización de la soja Roundup Ready (RR) resistente al glifosato.

Dicho marco legal fue acompañado por medidas económicas vinculadas a la apertura comercial, estabilización de precios, privatizaciones, sumado a eliminaciones impositivas agropecuarias permitió la importación de maquinarias y estos insumos químicos a bajo costo. (Souza Casadinho,2017)

En la actualidad, en base a datos del Instituto Nacional de Estadísticas y Censos (INDEC) la soja y sus derivados (harina, forraje que es utilizado como alimento para animales) fueron el principal bien de exportación en el año 2018 recaudando unos 15 mil millones de dólares. ${ }^{8}$

\section{Legislación}

La utilización de agroquímicos, en la provincia de Buenos Aires, se rige por la ley 10699 de Protección a la salud humana, recursos naturales y la producción agrícola del año 1988. La misma, en su art. 2, regula la elaboración, formulación, distribución y comercialización de todos los agroquímicos (como funguicidas, insecticidas, acaricidas, fertilizantes, etc.) utilizados para la protección y desarrollo de la producción vegetal.

El órgano competente para cumplir la finalidad de la ley es el Ministerio de Agroindustria provincial con la coordinación del Ministerio de Salud y podrá convenir con Universidades y entidades oficiales públicas y privadas programas de capacitación e investigación sobre el manejo y uso de agroquímicos en vías de aumentar su eficiencia y evitar riesgos de intoxicación y contaminación al ambiente. Además, el Ministerio de Agroindustria tendrá a cargo la actualización de registros de inscripción los fabricantes, formuladores y depósitos de los productos que componen el art. 2 de esta ley. El art. 6 establece que se

8 Datos del INDEC en Informes Técnicos vol. 3 n $n^{0} 28$, Comercio Exterior vol. $3 \mathrm{n}^{\circ} 4$ sobre "Complejos Exportadores" (2018) publicado en marzo de 2019. Disponible en: https://www. indec.gob.ar/uploads/informesdeprensa/complejos_03_19.pdf 
deberá contar con un ingeniero agrónomo para la elaboración de los agroquímicos.

Los agroquímicos se clasifican en:

“a) De uso y venta libre: son aquellos cuyo uso de acuerdo a las instrucciones, prevenciones y modo de aplicación aconsejado, no sean riesgosos para la salud humana, los animales domésticos y el medio ambiente.

b) De uso y venta profesional: son aquellos que, por sus características, su uso resultare riesgoso para los aplicadores, terceros, otros seres vivos y el medio ambiente.

c) De venta y uso registrado: son los no encuadrados en las categorías anteriores, cuya venta será necesario registrar a los fines de permitir la identificación de los usuarios." (Ley 10699, 1988, art.7)

Los agroquímicos "de uso y venta profesional" y los "de venta y uso registrado" requerirán de una "Receta Agronómica Obligatoria", emitida por un ingeniero agrónomo u otro título habilitante, para ser comercializados. Este artículo vislumbra el impacto que pueden ocasionar determinados agroquímicos en la salud humana por su toxicidad.

El Ministerio de Agroindustria, junto a los municipios, ejerce el poder de policía de esta normativa acorde al art. 16. Este organismo de aplicación podrá solicitar a la Secretaría de Agricultura, Ganadería y Pesca de la Nación la exclusión de un agroquímico de la nómina de productos autorizados debido a su alta toxicidad u otra causa que hiciera peligroso su uso.

Dicha ley ha sido reglamentada por el Decreto 499/91. En este decreto se trata el registro para aquellos que decidan solicitar la habilitación para realizar las actividades mencionadas en el art. 2 de la ley 10699. Detalla los requerimientos para el funcionamiento de las empresas que aplican agroquímicos como la inscripción en un registro que habilitará la Dirección de Agricultura y Sanidad Vegetal y la indumentaria necesaria para realizar la actividad. Estas empresas pueden ser de aplicación terrestre donde el control de plagas en el radio urbano 
deberá contar con la autorización del organismo municipal; mientras que las empresas de aplicación aérea deberán acreditar inscripción en la Dirección General de Aeronáutica Civil y aprobación de la Dirección de Agricultura y Sanidad Vegetal para realizar fumigaciones y operar a una distancia no menor de $2 \mathrm{~km}$. de centros urbanos. Se regula una receta agronómica que debe indicar el diagnóstico y prescripción del agroquímico como la forma de aplicación. Se trata la necesidad de poseer un seguro para responder civilmente por las consecuencias de la actividad. Por último, menciona periodos de carencia donde no se deberán aplicar agroquímicos para reducir el impacto en el ambiente.

Respecto a los municipios tienen la potestad de ejercer el poder de policía a través de ordenanzas municipales para determinar, por ejemplo, las zonas de fumigaciones respecto a las distancias con el ejido urbano.

\section{Actualidad normativa}

A través de la resolución 246/18 de la provincia de Buenos Aires dictada el 17/10/2018 con aplicación, según su art. 1, al 1/1/2019 el Ministerio de Agroindustria impulsó la fumigación en zonas adyacentes, mencionadas en la normativa como zonas de amortiguamiento, sobre las zonas urbanas y colegios rurales, pero fuera del horario escolar de estas instituciones. Según dicha disposición ministerial se podría fumigar hasta un minuto antes del inicio de las clases sin tener en cuenta la contaminación al ambiente ni el impacto en la salud de los niños.

Lo normativa contenía un anexo que definía los términos de mayor importancia como la zona de amortiguamiento. Dicha zona era entendida como la superficie adyacente a determinadas áreas de protección que por su naturaleza y ubicación requerían un tratamiento especial. Las zonas de protección consistían en la zona urbana, residencial extraurbana, área de población dispersa, márgenes de cursos o cuerpos de agua, zonas de bombeo, establecimientos educativos y reservas naturales. En relación 
con el tratamiento especial para la zona de amortiguamiento, el art.3 establecía que la aplicación de los fitosanitarios necesitaría considerar las características intrínsecas del producto, como su toxicidad y tensión de vapor, la regulación necesaria del equipo y las condiciones meteorológicas antes y durante la aplicación. Respecto a la aplicación de agroquímicos en la zona de amortiguamiento contigua a zona urbana, residencial con maquinaria agrícola, montada o autopropulsada se requerirá la presencia de un profesional que intervenga en las previsiones para aplicarlos y la facultad de decidir la suspensión de su utilización en caso de no cumplir con sus previsiones.

El art. 5 fue el que más polémica generó ya que permitía la aplicación de agroquímicos en la zona de amortiguamiento contigua a establecimientos educativos fuera del horario escolar.

El 7 de enero del 2018, en la Ciudad de General Pueyrredón, una gran cantidad de actores trascendentales de la educación (Cátedras Libres de distintas universidades de todo el país como la UNLP, UBA, UNLZ, UNQ), la salud como Miryam K. de Gorban (Coordinadora General Cátedra Libre de Soberanía Alimentaria de Nutrición UBA), el ambiente como RENAMA (Red Nacional de Municipios y Comunidades que fomentan la Agroecología) y el CELS presentaron un comunicado dirigido a la Gobernadora María Eugenia Vidal bajo el título "La Resolución del Veneno (Resolución 246 MAGP)" detallando su impacto. En dicho comunicado expresaron que la normativa no especificaba distancias mínimas entre la aplicación de agroquímicos y las viviendas donde reside la población y se permitía fumigar sobre reservas naturales y a los márgenes de arroyos, ríos y lagos. También era posible fumigar alrededor de establecimientos educativos instantes previos al inicio de las clases. Además, no se solicitaba una receta agronómica para la utilización de los fitosanitarios de forma contraria a lo establecido por el Decreto 499/91 en sus arts. 39 y siguientes. Finalmente manifestaban que esta resolución era regresiva respecto a las limitaciones en el uso de agroquímicos y afectaba al ambiente y la soberanía alimentaria. 
El 23 de enero del 2019, las abogadas María Florencia Casamiquela y Claudia Patricia Bogliolo presentaron una acción de amparo en la localidad de Mercedes, en representación de una docente residente en la localidad de Chivilcoy, frente a la resolución 246 contra el Ministerio de Agroindustria y el Poder Ejecutivo Provincial detallando los límites que había establecido la Suprema Corte de Justicia de la Provincia de Buenos Aires en los casos "D.JE.F. s/acción de amparo" y "Picorelli Jorge O. y otros c. Municipalidad de General Pueyrredón s/Inconst. Ord. 21.296". Fundaban la vulneración del principio preventivo, precautorio y progresividad consagrados por la ley 25675 y el interés superior del niño de la Convención de los Derechos del niño con jerarquía constitucional. Por último, solicitaron una medida de no innovar y la suspensión de los efectos de la resolución.

Ante la presión social de organizaciones, sindicatos, docentes, investigadores y el amparo presentado por la abogada Casamiquela, se visibilizó las consecuencias de la resolución 246 del Ministerio de Agroindustria. Finalmente, el 16 de febrero de 2019, el mismo Ministerio dictó la resolución №24, publicada por el Boletín Oficial, para suspender por el plazo de un año la aplicación de la resolución 246 y modificó el art. 5 de dicha resolución para que se abstengan de fumigar en zonas linderas a establecimientos educativos. Esta nueva resolución propugna la creación de un equipo técnico multidisciplinario para elaborar un protocolo de aplicación de fitosanitarios en la zona de amortiguamiento.

\section{Jurisprudencia de la SCBA}

La Suprema Corte de Justicia de la Provincia de Buenos Aires, en los últimos casos que ha resuelto mantuvo una postura coherente con los parámetros de la ley general del ambiente y sus principios frente a la problemática de la aplicación de agroquímicos. A través de cada caso se detallarán los hechos y la opinión que ha brindado el máximo tribunal provincial, el 
cual se sustentó en el principio precautorio buscando proteger la salud humana y al ambiente.

Cabe destacar la irrupción del principio precautorio en la lógica jurídica como una directriz que reside sobre una duda frente al común daño jurídico vinculado a la certeza. Esta clase de daño incierto puede presentar sus consecuencias en el futuro y de manera impersonal, otorgando una herramienta para los derechos de incidencia colectiva. (Cafferatta, 2009).

1) En el año 2012 bajo los autos "D.JE.F. s/acción de amparo", M.C.M y V.A.F. en representación de sus hijos menores dedujeron acción de amparo contra el propietario de una parcela rural contigua a su vivienda que los actores ocupaban en el Partido de Alberti, el cual formaba parte de un grupo habitacional construido por el Fondo Nacional de la Vivienda (FONAVI).

Los actores solicitaban que la aplicación de plaguicidas se efectuara sobre una distancia de 200 metros entre su vivienda y la parcela del demandado con el fin de mitigar los efectos contaminantes. Fundaban su pretensión en el hecho acontecido los días 20 de octubre y 11 de noviembre de 2008 cuando padecieron en sus propios cuerpos el contenido de los agroquímicos tras la fumigación realizada por el vecino

La familia requirió una medida cautelar innovativa para suspender la fumigación, la cual les fue otorgada. Ante esta resolución el propietario solicitó la modificación de la medida cautelar que fue resuelto en sentido favorable permitiéndosele fumigar a una distancia de 30 metros respecto a la vivienda de la parte actora. Tras esta decisión que aquejaba sus derechos, la familia recurrió a la Cámara de Apelación y Garantías en lo Penal del Departamento Judicial de Mercedes, la cual ratificó lo dispuesto por la primera instancia y desestimó las pruebas presentadas por los recurrentes.

Ante esta situación, la familia interpuso el recurso extraordinario de inaplicabilidad de ley frente a la SCBA fundado en la violación del Preámbulo y los arts. 33, 41 y 43 de la Constitución Nacional, la Convención sobre los Derechos del Niño y Tratados 
Internacionales; 20, 28 y 36 inc.8 de la Constitución provincial; la Ley Nacional 25.675; leyes provinciales $7166 ; 10.699$ y su decreto reglamentario 499/91; 11.723; Arts. 1071 y 2618 del Código Civil. Notoriamente fueron vulnerados los principios del derecho ambiental surgidos de la ley nacional 25675 y manifestaron incongruencia de la sentencia de la Cámara de Apelación donde existió una absurda valoración de la prueba.

Resulta interesante la interpretación de los magistrados de la SCBA sobre el derecho al ambiente entendiéndolo como una ampliación de la personalidad humana donde el hombre forma parte del entorno natural y lo siente como un valor interior superando la visión de relación de dominio sobre el ambiente. Por lo tanto, es indispensable garantizar el derecho al ambiente con el fin de propiciar un equilibrio ecológico y un bienestar de los individuos comprendiendo que estos últimos requieren de condiciones aptas para gozar de dicho bienestar para sobrevivir.

Respecto a la desestimación de pruebas aportadas por los actores en instancias anteriores, la SCBA entendió que existía una duda razonable acerca de la peligrosidad de las fumigaciones, aunque no se contara con una certeza científica, y la petición debía ser decidida favorablemente por aplicación del principio precautorio.

La SCBA entendió que no era necesaria la comprobación de un daño concreto para una protección inmediata ya que la fumigación a una escasa distancia de la vivienda de los actores implicaba una conducta potencialmente lesiva al ambiente. La Suprema Corte resolvió de manera favorable el recurso, revocándose la sentencia de Cámara, y haciendo lugar a la pretensión del amparo acorde a las distancias determinadas por la Ordenanza 1690 (la ordenanza establecía una distancia de 1000 metros respecto al ejido urbano para la realización de fumigaciones en condiciones climáticas favorables).

2) Durante el año 2014 se suscitó una nueva controversia sobre la aplicación de fitosanitarios en la localidad de General Pueyrredón. En los autos "Picorelli Jorge Omar y 
otros c/Municipalidad de General Pueyrredón s/Inconst. Ord. No21.296" los actores en representación de sus hijos menores promueven recurso de inconstitucionalidad de los art. 19, 23, 27 y 28 de la Ordenanza Municipal No21.296/2013 considerando que la misma vulneraba la Constitución Nacional (art.41), la Constitución provincial (art.28), la Ley General del Ambiente 25.675, la Ley de Residuos Peligrosos 24.051, la ley provincial 5965 de protección a las fuentes de provisión y a los cursos y cuerpos receptores de agua y a la atmósfera, Ley 11.723 y arts. 25 y 27 inc. 17 de la Ley Orgánica de las Municipalidades.

La Ordenanza 21296/13 modificó la zona de seguridad frente a fumigaciones de 1000 metros (como establecía la Ordenanza 18.740/08) a 100 metros de plantas urbanas y solo prohibió el uso de plaguicidas de síntesis cuando la anterior resolución prohibía el uso de cualquier producto químico sobre zona de seguridad. La nueva ordenanza prohibió los pulverizadores autopropulsados en un radio de 200 metros de centros urbanos, cursos de agua, escuelas y centros de salud, aunque permitiendo en la misma franja la aplicación con "mochila" cuando la prohibición de la anterior normativa era integral para estas prácticas. Por último, sobre la Franja Transicional Periurbana se permitía, bajo la nueva resolución, la aplicación de productos de síntesis de Banda IV como el glifosato.

Los magistrados de la SCBA realzaron la importancia del principio de progresividad tras la vulneración de derechos por la nueva ordenanza entendiendo que la misma los había sustituido por derecho inferiores.

Continuando con los lineamientos expresados en el caso "D.JE.F. s/acción de amparo", la SCBA manifestó que esta actividad antrópica de fumigación resulta potencialmente nociva, en concordancia con el principio precautorio de la ley 25.675, al entorno y a la salud de la población. Por las razones expuestas, la SCBA resolvió la suspensión de los arts. 19, 23, 27 y 28 de la Ordenanza 21.296/2013 de la Municipalidad General de Pueyrredón, por ende, retomó vigencia el régimen anterior de la Ordenanza 18.740. 
3) En el año 2015 la SCBA se expide sobre el caso "ASHPA. Amparo. Recurso de inaplicabilidad de ley" donde la asociación civil "ASHPA" Centro de Educación Agroecológico, representada inicialmente por la Clínica de Derecho Ambiental de la Facultad de Ciencias Jurídicas y Sociales (UNLP), había presentado una acción de amparo ambiental contra la titular y el explotador del predio ubicado en las Parcelas 609 y 610, delimitadas por la avenida 21 y la calle 41 de la localidad de Presidente Perón, Guernica y contra el municipio y la Provincia de Buenos Aires. La parte actora solicitaba la cesación de manera inmediata y definitiva de la pulverización, fumigación o cualquier otra forma de aplicación de agroquímicos que ocasionaren un daño ambiental colectivo. Además, requerían que los entes públicos ejercieran el poder de policía ambiental sobre la actividad efectuada por los demandados.

El pedido de ASHPA fue desestimado por el Juzgado de Garantías en lo Penal N³ del Departamento Judicial de La Plata quien fundó su resolución en la inexistencia de vulneración de derechos al momento de iniciar la acción y que no se había constatado incumplimiento de la ley provincial 10.699. Luego la asociación presentó un recurso de apelación frente a la Cámara de Apelación en los Contencioso y Administrativo quien confirmó lo dispuesto por la primera instancia y manifestó que actualmente no se realizaban labores de fumigación y la última efectuada se remontaba a un año.

Frente a esta decisión, la parte actora interpuso recurso extraordinario de inaplicabilidad de ley ante la SCBA. La asociación desestimó los fundamentos de la Cámara y argumentó que los demandados ya habían reconocido la utilización de agroquímicos en varias campañas y que la última siembra había sido realizada en noviembre de 2011. A través de este recurso, ASHPA destacó que la Cámara se desentendió del análisis del art. 43 de la Constitución Nacional al excluir expresamente la amenaza e inminencia del daño de las fumigaciones. Por ende, el estado de los hechos se concibe con el continuo peligro que persiste de manera latente entre los demandados que 
explotaban del predio y el resto de la comunidad, entendiendo que el criterio de la Cámara resultaba un supuesto de absurdo ya que sería admisible un amparo solamente cuando se estén aplicando agroquímicos. ${ }^{9}$

Por estas razones, fundaron su reclamo en priorizar los bienes jurídicos como la vida y la salud de las personas y aplicar los principios, como el precautorio, desarrollados por la ley 25.675. También citaron el antecedente de "D.J. E.F. s/Acción de Amparo" sobre el daño potencial de las fumigaciones en contraposición a este caso donde se ha aplicado erróneamente el bloque de legalidad ambiental.

Por último, la asociación entendió que se vulneraban los fines de la ordenanza 708/2010 dictada por el Concejo Deliberante de Presidente Perón como la protección a la salud humana y los recursos naturales que disponía su art.3 y el art. 12 que prohibía las aplicaciones aéreas de productos agroquímicos, de todo tipo, en el territorio del Presidente Perón y la aplicación terrestre sobre el área urbanizada. La ordenanza disponía la necesidad de contar con una barrera vegetal para la aplicación de agroquímicos. Contando con una normativa específica que regulaba la actividad de aplicación de fitosanitarios, la parte actora entendió que las autoridades estatales no ejercieron el poder de policía.

Finalmente, la SCBA revocó la sentencia impugnada y ordenó al demandado que se abstenga en realizar tareas de fumigación terrestre con los productos incluidos en el ámbito de aplicación de la ley 10.699 (art.2) y Ordenanza 708/10 de la Municipalidad de Presidente Perón (arts. 3, 4 y 13) dentro de la zona prohibida por dicha norma municipal.

4) Durante el año 2016 el abogado Luis Fernando Cabaleiro interpuso acción de amparo contra la empresa "Papel Prensa S.A."

\footnotetext{
9 Las fumigaciones dejan consecuencias en el ambiente y a razón de las condiciones climáticas, como la erosión eólica, hasta pueden extenderse en el espacio territorial como sucedió en el Río Paraná que presentaba muestras de glifosato. Disponible:http://www.maximaonline. com.ar/Nota49347el_investigador_damin_marino_expuso_sobre_glifosato_y_el_modelo_ productivo Ultimo acceso 18/5/2019
} 
a causa de la explotación forestal en el predio "María Dolores" ubicado en el paraje de Palentenlén del Partido de Alberti. El actor cuestionaba la falta de estudios de impacto ambiental y que la parte demandada carecían de la autorización de una autoridad competente para llevar a cabo su actividad en base a lo dispuesto las leyes provinciales 11.723, 12.442 y 12.952, art.5 de la ley nacional 25.080 y el art.11 de la ley 25.675. Bajo estos términos, el actor solicitaba la suspensión de la actividad forestal hasta que se complete el procedimiento de Evaluación del Impacto Ambiental.

Además, el abogado Cabaleiro planteaba que la empresa incumplía con la ley provincial 10.699 y su decreto reglamentario 499/91 teniendo en cuenta que la inspección del O.P. D.S. no poseía actas de trabajo sobre aplicación de agroquímicos, de recetas agronómicas con intervención profesional y sobre la disposición final de los envases de los productos utilizados. También manifestó la utilización, por parte de la demanda, de agua subterránea para riego y aplicación de plaguicidas sin el cumplimiento de las exigencias que imponía la ley 12.257. El fundamento del actor fue desestimado en las instancias anteriores.

Por parte de la empresa, argumentaban que existía una ordenanza en el municipio Alberti por la cual podían utilizar agroquímicos. La aplicación de agroquímicos no se autoriza de manera implícita por la existencia de una ordenanza y debe ser acorde a lo dispuesto por la ley provincial 10.699 y su decreto reglamentario 499/91. En este caso se vulneraban ambas normativas ya que no se contaba con una receta agronómica emitida por un profesional, tampoco se explicaba cuál sería el destino de los envases de estos productos químicos y no poseían un estudio de impacto ambiental sobre la actividad forestal.

Finalmente, la SCBA ordenó detener las actividades de plantaciones por carecer de una evaluación de impacto ambiental ateniéndose a la omisión del organismo provincial en dicho control sobre un predio con una plantación de 1120 árboles por hectárea en un predio de 1834 hectáreas envases y por ende 
ocasionaba una amenaza ambiental. También determinó que la demandada debería gestionar el destino final de los envases de los agroquímicos.

\section{Conclusiones}

Durante el presente trabajo se ha podido apreciar que la utilización de los agroquímicos es una cuestión que pone en juego los intereses de diversos actores con gran injerencia en la alimentación, fabricación de medicamentos y en la política diaria de los gobiernos de turno.

La influencia de una multinacional como Monsanto-Bayer se plasma en el control del mercado para la maximización de la producción de alimentos y sus constantes lobbies tienen sus logros en resoluciones como la 246/18 emitida por el ministro Leonardo Sarquis (ex gerente de la división Semillas de Monsanto por 3 años). La presión social desarrollada por organismos no gubernamentales, docentes, científicos y el apoyo del CELS gestaron la suspensión de la resolución por el plazo de un año.

Resulta claro e impactante el testimonio del neonatólogo Medardo Ávila, de la Red de Médicos de Pueblos Fumigados, sobre las consecuencias de las fumigaciones con glifosato en zonas rurales de la Argentina y su mayor incidencia de cáncer y malformaciones al nacer: "Lo que vemos, los médicos, es que las personas se enferman de manera diferente. Se mueren ahora principalmente por cáncer, desde que se empezó a fumigar y se usaron estos agrotóxicos de forma masiva”. También indica que "claramente, las poblaciones agrícolas de Argentina tienen en este momento tres veces más cáncer que las poblaciones de las ciudades" y asegura que en el campo de 100 nacimientos seis son de niños con malformaciones. ${ }^{10}$

\footnotetext{
10 Nota del medio Perfil, el 18/7/2018, titulado "El drama del glifosato en el campo argentino y una legislación ausente":

https://www.perfil.com/noticias/salud/el-drama-del-glifosato-en-el-campo-argentino-y-unalegislacionausente.phtml?rd=1\&fbclid=IwAR2nHYHKYH12MgGuk2904ydSYZpF726zB9yOHloG 4i5buoHvKMqjrapbV80\&rd=1 Último acceso 18/5/19
} 
En concordancia con la opinión del Dr. Medrado, el Jurado en la Corte Federal de San Francisco de los Estados Unidos dictaminó que el Roundup es responsable del cáncer que padece Edwin Hardeman, residente de California (Hardenman sufre un linfoma Hodgking). ${ }^{11}$

En miras del agronegocio, los intereses empresariales buscan invisibilizar las consecuencias de los fitosanitarios, previamente expuestas, y concretar sus acuerdos con resoluciones ministeriales aunque implique fumigar en adyacencias a establecimientos educativos.

Ante estas medidas se requiere de abogadas y abogados comprometidos en defender los derechos a una vida digna, la salud de los ciudadanos y del ambiente.

De una formación académica que observe la realidad social a través del Derecho Ambiental, el cual es considerado como un sistema protector de intereses colectivos que contiene todos los elementos del ambiente natural y humano en su conjunto (Jaquenod de Zsögön, 1991), comprendiendo que sin el cuidado del ambiente mermaría la calidad de vida de todos sus pobladores.

Por último, resulta fundamental que los tribunales inferiores continúen la línea de la Suprema Corte de Justicia de la Provincia de Buenos Aires en protección de los principios emanados por la Ley General del Ambiente y acompañar sus decisiones con informes e investigaciones realizados por investigadores $\mathrm{y}$ médicos para fundamentar de una manera multidisciplinaria.

\section{Referencias Bibliográficas}

Cafferatta N. (2009), "Los Principios y reglas del Derecho Ambiental", Buenos Aires.

\footnotetext{
11 Nota del medio Reuters, del 21/03/2019, bajo el título "Jurado en EEUU falla contra Bayer en caso de cáncer por herbicida Roundup". Disponible en https://Ita.reuters.com/ articulo/bayer-glifosato-jurado-idLTAKCN1R0208 Último acceso 18/5/2019
} 
Gutman G. (2012), "Desarrollo de la Agrobiotecnología en la Argentina. Nuevas tecnologías renovadas problemáticas", Revista Voces en el Fénix, Facultad de Ciencias Económicas (UBA).

Jaquenod de Zsögön S. (1991), "El Derecho ambiental y sus principios rectores", Dykinson.

Ley 10.699 de Protección a la salud humana, recursos naturales y la producción agrícola mediante y su decreto reglamentario 499/91, normativa correspondiente a la provincia de Buenos Aires.

Organización de las Naciones Unidas para la Agricultura y la Alimentación (1985), Código Internacional de Conducta para la Distribución y Utilización de Plaguicidas. Disponible en: http://www.fao.org/3/a-a0220s.pdf

Sarandón S. y Flores C. (2014), "Agroecología: bases teóricas para el diseño y manejo de agroecosistemas sustentables", EDULP, Universidad Nacional de La Plata.

Souza Casadinho J. (2017), "Veinte años de cultivos transgénicos en Argentina", X Jornadas de Estudios Interdisciplinarios Agrarios y Agroindustriales, Faculta de Ciencias Económicas (UBA).

\section{Artículos utilizados}

Nota del medio, de Gualeguaychú, Máxima online, el 10/3/2018 bajo el título "El investigador Damián Marino expuso sobre glifosato y el modelo productivo" que trata la prohibición en el uso de glifosato en dicha localidad. Disponible en http://www. maximaonline.com.ar/Nota-49347-el_investigador_damin_ marino_expuso_sobre_glifosato_y_el_modelo_productivo

Nota del medio Perfil, el 18/7/2018, titulado "El drama del glifosato en el campo argentino y una legislación ausente" Disponible en https://www.perfil.com/noticias/salud/el-drama-del-glifosato-en-el-campo-argentino-y-una-legislacionausente.

1?rd=1\&fbclid=IwAR2nHYHKYH12MgGuk2904ydSYZpF726zB9yO HloG4i5buoHvKMqjrapbV8Q\&rd=1

Nota del medio infocampo.com.ar, del día 17/8/2018, bajo el título

"Confirman que dos agroquímicos interfieren en la polinización 
de las abejas". Disponible en https://www.infocampo.com.ar/ confirman-que-dos-agroquimicos-interfieren-en-la-polinizacion-de-las-abejas/

Nota del medio Infobae, del día 11/2/19, bajo el título "Más de la mitad de la verdura que llega al Mercado Central queda descartada por exceso de agrotóxicos detectado en sus laboratorios" Disponible en: https://www.infobae. $\mathrm{com} /$ tendencias/ecologia-y-medio-ambiente/2019/02/11/ mas-de-la-mitad-de-la-verdura-que-llega-al-mercado-central-queda-descartada-por-exceso-de-agrotoxicos-detectadoen-sus-laboratorios/

Nota del medio Reuters, del 21/03/2019, bajo el título "Jurado en EEUU falla contra Bayer en caso de cáncer por herbicida Roundup”. Disponible en https://lta.reuters.com/articulo/ bayer-glifosato-jurado-idLTAKCN1R02Q8

Nota realizada por el medio Infobae del día 11/4/2019 bajo el título "Contaminación de agua y graves problemas de salud: ordenaron suspender la fumigación con agroquímicos en Pergamino". Disponible en el link: https://www.infobae. com/sociedad/2019/04/10/contaminacion-del-agua-y-gravesproblemas-de-salud-ordenaron-suspender-la-fumigacion-conagroquimicos-en-pergamino/

Nota del medio Perfil del día 16/4/19 bajo el título "Peritos de la Corte Suprema confirman que el agua de Pergamino contiene 18 agroquímicos" Disponible en el link: www.perfil.com/ noticias/sociedad/corte-suprema-confirmo-contaminacionagua-pergamino-tiene-18-agroquimicos-riesgo-salud-humana. phtml 